\title{
Trends in HIV prevalence from 2008 to 2012 among young adults in Port Harcourt, Nigeria
}

\author{
Iheanyi Omezuruike Okonko, Lasbry Chidi Nnodim
}

Medical Microbiology Unit, Department of Microbiology, University of Port Harcourt, P.M.B. 5323, Choba, East-West Road, Port Harcourt, Rivers State, 500102, Nigeria;

\begin{abstract} data generated was exposed to Fisher's Exact Test. counselling and testing services also increased.

DOI: http://dx.doi.org/10.4314/ahs.v15i3.11 Health Sci. 2015;15(3):776-88. doi: bttp:// dx.doi.org/10.4314/abs.v15i3.11

\section{Introduction}

The United Nations has termed HIV and AIDS the greatest overwhelming public health problems that the world has ever encountered ${ }^{1,2}$. The epidemic of HIV lines amid the paramount infectious disease menaces in the past ${ }^{1,3}$. The HIV widespread lingers to be a load worldwide and offers grave public health glitches in emerging countries particularly in Nigeria ${ }^{1,4,5}$.
\end{abstract}

Background: The pandemic of HIV lines amongst the utmost infectious disease menaces in antiquity. HIV remains a problem worldwide and it's a grave health snags in developing nations particularly in Nigeria.

Objective: This study focused on "trends in HIV reporting from 2008 to 2012 among young adults in Port Harcourt, Nigeria. Methods: Secondary data were collected from BMSH, Port Harcourt using a Performa specifically intended for this determination. Socio-demographic data for the subjects were recovered from coded patients' medical records kept at BMSH. The

Results: The study showed that a total of 3081 HIV-positive cases were reported between 2008 and 2012. The HIV trend were not well defined, it peaked in 2009(36.6\%) and 2008(32.8\%) and a decrease in 2011(16.6\%), 2012(8.3\%) and 2010(5.7\%). A 3.8\% increase was observed between 2008 and 2009 and 30.9\% decrease between 2009 and 2010. However, the prevalence seemed to stabilize between 2009 and 2012. HIV patterns among various age-groups is not well-defined, it rose with increasing age and peaked at 26-30years $(35.7 \%)$ after which it declined. Sex differences $(\mathrm{P}<0.05)$ in the trend was observed. Males ages 26-30years showed uniform pattern with an increasing trend while 36-40years showed decreasing trend except in 2009(34.1\%). Females ages 26-30years showed uniform pattern with an increasing trend from 2008(21.7\%) to $2010(41.9 \%)$ and decreased from $41.9 \%$ (2010) to $36.5 \%(2012)$. The low HIV prevalence in 2010 could be attributed to the fact that the proportion of centers giving ART enlarged from 2005 to date. Health care facilities providing HIV/AIDS

Conclusion: The long decades fight against HIV especially in Rivers State is making progress, though an unstable one. The observed increase in years with high HIV prevalences calls for an intensified focus of intervention.

Keywords: AIDS, Anti-retroviral therapy (ART), Health facilities, HIV, Prevalence Trends.

Cite as: Okonko IO, Nnodim LC. Trends in HIV prevalence from 2008 to 2012 among young adults in Port Harcourt, Nigeria. Afri

\author{
Corresponding author: \\ Iheanyi Omezuruike Okonko \\ Medical Microbiology Unit, \\ Department of Microbiology, \\ University of Port Harcourt, \\ P.M.B. 5323, Choba, \\ East-West Road, Port Harcourt, \\ Rivers State, Nigeria; \\ E-mail: iheanyi.okonko@uniport.edu.ng \\ Tel.: +2348035380891
}

Over the years, Rivers State of Nigeria has witnessed a rising trend in HIV/AIDS infection ${ }^{4}$. The plague of HIV and AIDS has persisted to establish grave socio-economic and public health problems for more than two eras. The epidemic is predominated by HIV-1 first found in $1983^{6,7}$. HIV-1 has remained liable for most HIV occurrences all over the world, whereas HIV-2 is originated principally in West Africa ${ }^{8}$ in 1987 and has not revealed any substantial blowout since then ${ }^{6,7}$. HIV-2 is not spread as easily as HIV-1 and the time between first infection and disease is usually elongated compared to HIV-1 ${ }^{6,7,9}$. Nevertheless HIV-1/2 is transmitted predominantly by sexual contact, perinatally and blood transfusion. HIV-2, nevertheless, is not proficiently spread likened to HIV-1 ${ }^{1,10}$. The study by Olaleye et al. ${ }^{11}$ and Abimiku et al. ${ }^{12}$ revealed HIV-1 to be most predominant and virulent mainly present in Nigeria, East and Central Africa, United States Europe and Asia, whereas HIV-2 is principally narrowed to West Africa ${ }^{1}$. 
Nigeria is the largest proportion of black people in the world with a population of more than 162 million $^{13-16}$. The HIV/AIDS epidemic has already devastated Nigeria, with nearly a million people dead and more than two million children orphaned ${ }^{5}$. In unfledged and evolving countries, it has overturned several of the socio-economic, development and health improvements over three decades now as manifested among others in life anticipation at birth and infant death rate ${ }^{13,17}$. HIV is a major factor contributing to the declining life expectancy rate from 54 years in 1991 to 48 years in $2010^{13}$.

The HIV pandemic has likewise enabled the recurrence of pulmonary tuberculosis and other unscrupulous infections. Footings in the proportions of persons with HIV, Nigeria was next to South Africa and India with the uppermost load of HIV in the world ${ }^{18}$. Though, Nigeria was recently rated as second country in the world with the uppermost HIV burden following the current amendment that estimated $<3$ million people with HIV in India ${ }^{19}$. Previous reports showed that estimation of 33.3 million individuals globally were likely to be plague-ridden with HIV as at $2009^{13,17}$. About 22.5 million lives in the sub-Saharan Africa while 2.98 million were in Nigeria. Furthermore, Nigeria is second to South Africa (5.6 million) with 3.1 million persons existing with HIV ${ }^{13-18,20}$. Approximately 215,000 people died from HIV in $2010^{13}$. Thus, Nigeria contributed $10 \%$ of the world-wide HIV load ${ }^{13}$.

After the index report on AIDS in Nigeria (1986), the spates have unrelenting to advance. The chauffeurs of the widespread of HIV in Nigeria include high rates of STIs in susceptible clusters, high illiteracy, poverty, general lack of apparent personal risk and low condom use $^{21}$. The first HIV/AIDS sentinel study in Nigeria was conducted in 1991 with $1.8 \%$ prevalence reported. The index HIV study showed 1.8\% prevalence in 1991. This was followed by 3.8\% in 1993, 4.5\% in 1996, 5.4\% in 1999 and a 5.8\% peak in 2001. From 2001 a somewhat decline in trends were noted, starting with $5.0 \%$ in $2003,4.4 \%$ in $2005,4.6 \%$ in 2008 and $4.1 \%$ in $2010^{13-}$ $17,22-23$. It stabilized between $4.4 \%$ (2005) and $4.1 \%$ in $2010^{13-17}$. However, $4.6 \%$ prevalence reported in 2008 presented a slim hitch in the sliding pattern, thus engendering some attention ${ }^{13-17}$. The median HIV prevalence in the country in 2012 was $4.1 \%{ }^{24}$. It is now clear that HIV prevalence in the country is relatively stable. This positive trend is largely attributed to effective reporting and intervention system ${ }^{25}$.

In 2010, 4.1\% national prevalence of HIV was reported for Nigeria ${ }^{17}$. According to the study, North Central Zone $(7.5 \%)$ was the highest, and South-South region $(6.5 \%)$ was next ${ }^{17}$. In relation to location, there were similar trends in all the region with North-Central and South-South regions as having topmost urban prevalence of HIV $(8.2 \%$ each) while South-South regions top the rural prevalence of HIV (4.2\%). In relation to states, Rivers State was found to be $6.0 \%$ with Bori $(8.0 \%)$ leading, followed by Bonny $(5.9 \%)$ and Port Harcourt $(5.5 \%)^{13-17}$.

In the 2008 HIV sentinel study, HIV was most predominant in females aged 25-29 years (5.6\%) and 3034 years $(4.9 \%)$. In $2007,3.6 \%$ prevalence of HIV was reported in the national population-based study with no significant sex related disparity ${ }^{17,26}$. Built on the inclusive national prevalence of $4.1 \%$ found in 2010 , it is projected that 3.1 million persons in Nigeria are existing with HIV and AIDS. And 1.5 million of them need ARV drugs ${ }^{13-17}$ while 281,180 novel infections ensued ${ }^{17}$. In the same vein, it is projected that people needing ART has considerably escalated to $1,512,720$; somewhat owing to the upsurge in continued existence of person living with HIV/AIDS (PLWHA), the emergent inhabitants as well as the variation in HIV treatment/ management plans as specified that HIV persons having CD4 less than 350 should be retained on ART. This number is anticipated to upsurge in the prospect owing to the similar motives ${ }^{17}$.

The widespread of HIV, as censored through predominance proportions, seems to indicate some steadiness in the HIV trends at the national level; while extensive discrepancy exist in different States ${ }^{17}$. HIV occurrence has reliably stayed low in some States and high in others. Whereas the occurrence has shown a steady drop in some States, it has been inconsistent in others ${ }^{13,17}$.

By States, HIV prevalence as shown in Figure 1 and 2 clearly varies. While HIV/AIDS tends to be generally low in most parts of the country, the highest numbers of HIV prevalence were found mostly in Benue, FCT, Anambra, Baylesa and Akwa Ibom States of the feder$\operatorname{ation}^{22-23,25}$. 
These marked differences in the prevalence rates among these states could be due to a number of factors including but not limited to cultural differences, varying levels of education, religion and differing socio-economic structures. Indeed, there must be interplay of these factors on HIV/AIDS outcome in these states. Hence, this retrospective study focused on assessing the trend of HIV among young adults, ages $16-40$ years in Port Harcourt, Rivers State, Nigeria over a period of time (2008-2012).

Figure 1: HIV/AIDs prevalence by States in Nigeria, 2012. Source: Nigeria National Agency for the Control of AIDS, 2012

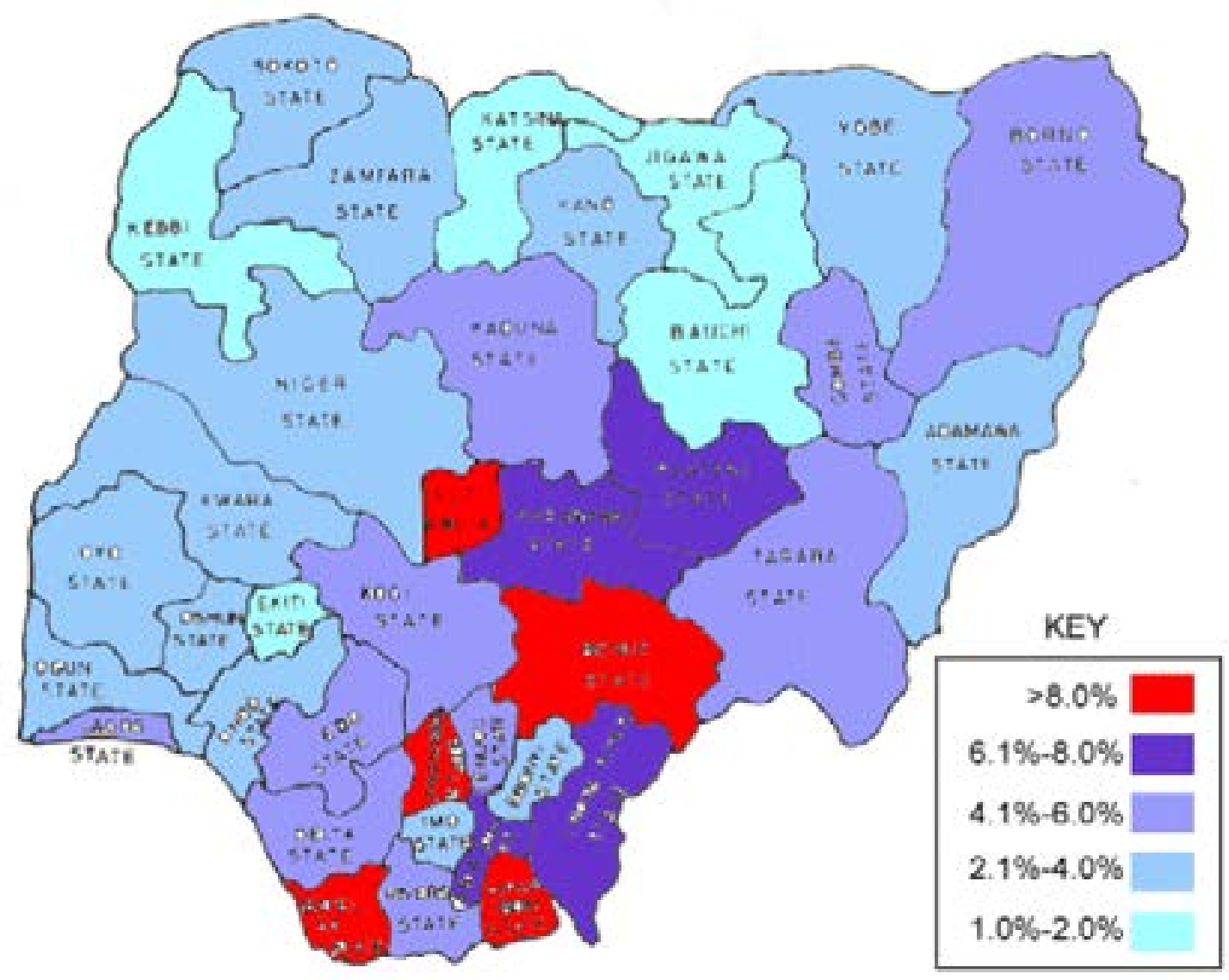

\section{Methodology}

\section{Study strategy}

This is a retrospective hospital based study. in the imperative to find a sample typical of the state, young adults ages 16-40 years old presenting at the Braitwhyte Memorial Specialist Hospital (BMSH) were selected to discover among younger people as a novel viewpoint to dissect HIV occurrence in Nigeria. To further buttress this, BMSH is a frequently used health-facility in Rivers State, Nigeria, which by feature of its setting delivers tertiary health-care services.

\section{Study area}

The trends of HIV prevalence in Port Harcourt was carried out using secondary data collected from Braitwhyte Memorial Specialist Hospital (BMSH), in Port
Harcourt, River State, Nigeria. Port Harcourt (Igbo: Diobu, Iguocha or Ugwuocha; Pidgin: "Po-ta-kot") is the capital of Rivers State, Nigeria ${ }^{27-29}$. It lies along the Bonny River in the Niger Delta. Coordinates: $4^{\circ} 53$ '23'N $6^{\circ} 54^{\prime} 18^{\prime \prime} \mathrm{E}$ and located in a city360 km2 (139 sq mi). From the Nigeria census in 2006, Port Harcourt had a population of 1,382,592 [30]. Port Harcourt city is in the Port Harcourt City Local Government Area, consisting of the former European quarters now called old Government reservation area (GRA) and New layout areas. The Port Harcourt Urban Area (Port Harcourt metropolis) is made up of the city itself and parts of Obio/Akpor Local Government Area [31]. It also has a tropical climate with very short dry seasons and lengthy and heavy rainy seasons. Only the months of December and January truly qualify as dry season months in 
the city. The harmattan, which climatically influences many cities in West Africa, is less pronounced in Port Harcourt. Port Harcourt's heaviest precipitation occurs during September with an average of $370 \mathrm{~mm}$ of rain. December on average is the driest month of the year; with an average rainfall of $20 \mathrm{~mm}$. Temperatures throughout the year in the city is relatively constant, showing little variation throughout the course of the year. Average temperatures are typically between $25^{\circ} \mathrm{C}-28^{\circ} \mathrm{C}$ in the city ${ }^{28-29}$.

\section{Ethical considerations}

This study was approved by the Research Ethics Committee of the Rivers State Hospital Management Board, Rivers State Ministry of Health, Port Harcourt, Nigeria.

\section{Study population}

The trends of HIV prevalence in Port Harcourt was carried out using secondary data collected from BMSH using a Performa specially designed for this purpose. The target population was young adults, ages 16-40 years old. Younger adults constitute the most practical group for this study as they are sexually active, easily defined and accessible. Younger adults were also generally representative of the sexually active population. This group of people was selected to search among younger people as an innovative perspective to dichotomize HIV occurrence in Nigeria. Sexual activities, ease of access, availability and other environmentally friendly issues were real motives for selecting this group of people.

\section{Data collection}

Demographic data (age and gender) for participants and their serological outcomes were retrieved from coded patients' medical records kept at BMSH. Data collected were based on age, sex results. Data collection tools were laboratory record book, request form, data form and monthly summary sheets.

\section{Sample collection and plasma preparation}

Patients presenting at the Braitwhyte Memorial Specialist Hospital (BMSH) had 5-mL of their blood collected aseptically by venepuncture using a disposable sterile needle and syringe ${ }^{32}$. The sample was transferred into a labeled blood sample tube containing EDTA anticoagulant. Plasma was centrifuged, separated and stored at $-20^{\circ} \mathrm{C}$ until used for serology $y^{32}$.

\section{Serological testing}

Samples presented at the Braitwhyte Memorial Specialist Hospital (BMSH) were screened for antibodies to HIV-1 \& -2 using two rapid kits, based on World Health Organization (WHO) systems. All samples were first screened with DETERMINE® HIV-1/2 test kits (Abbott laboratories). This is an immunochromatography (rapid) technique for measureable recognition of antibodies of all isotopes ( $\operatorname{IgA} \operatorname{IgG}$ and $\operatorname{IgM}$ ) precise to HIV-1 and HIV-2 concurrently in serum. Red coloured lines in the control and patient windows is indicative of a positive result while existence of the red coloured line in the control and its lack in the patient window is also indicative of a negative result. Non-Reactive samples were recorded as NEGATIVE. All REACTIVE samples were further tested using HIV-1/2 STAT-PAK ${ }^{\circledR}$ (Chembio Diagnostic Systems, Inc.)' test kits. These kits were intended chiefly to check for the existence of HIV-1 and/or HIV-2 antibodies in the blood. Samples which were REACTIVE with both DETERMINE and STAT-PAK test kits were recorded as POSITIVE. Samples that were REACTIVE with DETERMINE only and NON-REACTIVE with STAT-PAK test kits were recorded as DISCORDANT. All tests were done in line with the manufacturer's stipulations.

\section{Data analysis}

The trend analysis of HIV prevalence focused on relevant independent variables such as age, sex and year. The generated data were showed using descriptive statistics and exposed to Fisher's Exact Test for contrast of proportions to define any substantial association amid gender, age and infection rate. To associate the amount of HIV infected persons, the chi-square test was used at $95 \%$ confidence level. The analysis was completed after recording the data in a Microsoft Excel worksheet on a Windows- 2010 platform.

\section{Result}

The study on trends in HIV reporting among younger adults in Rivers State, Nigeria showed that a total of 3, $081(100.0 \%)$ young adults age bracket $(16-40$ years) were HIV-positive "between" 2008 and 2012. On the overall HIV was most prevalent in females $(69.5 \%)$ than their male counterparts $(30.5 \%)$. 


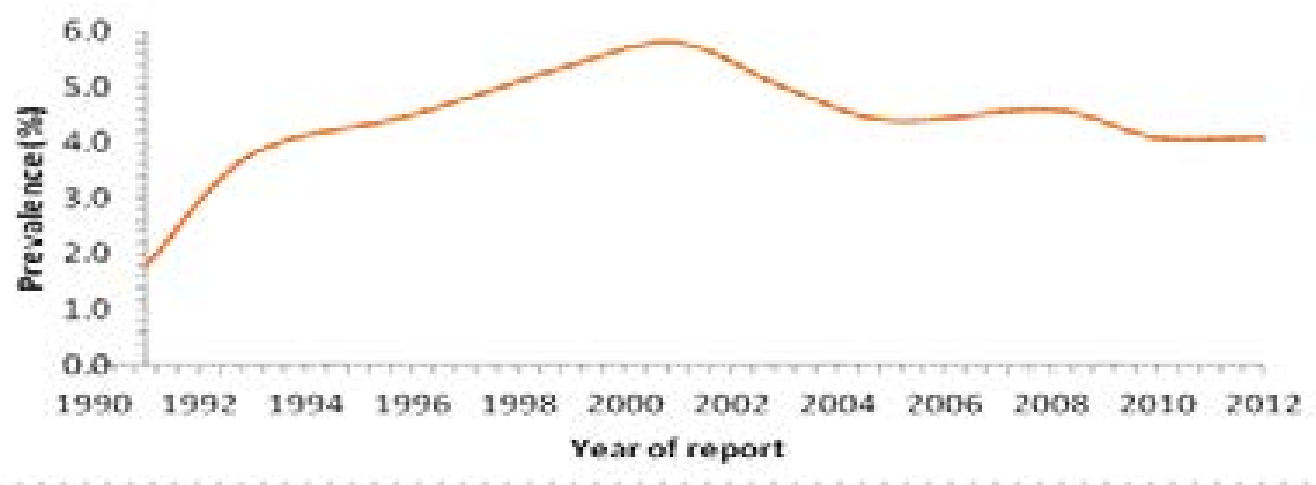

Figure 3 shows the trend of HIV prevalence among young adults. It showed that $1,010(32.8 \%)$ young adults were confirmed HIV-positive in 2008, 1,127(36.6\%) in $2009,176(5.7 \%)$ in $2010,512(16.6 \%)$ in 2011 and
$256(8.3 \%)$ in 2012. The trend of HIV prevalence among young adults from 2008-2012 were not well defined, which showed a peak in $2009(36.6 \%)$, followed by $2008(32.8 \%), 2011(16.6 \%), 2012(8.3 \%)$ and 2010 $(5.7 \%)$ [Figure 3].

Figure 3: Trends in HIV prevalence from 2008 to 2012 among young adults in Rivers State

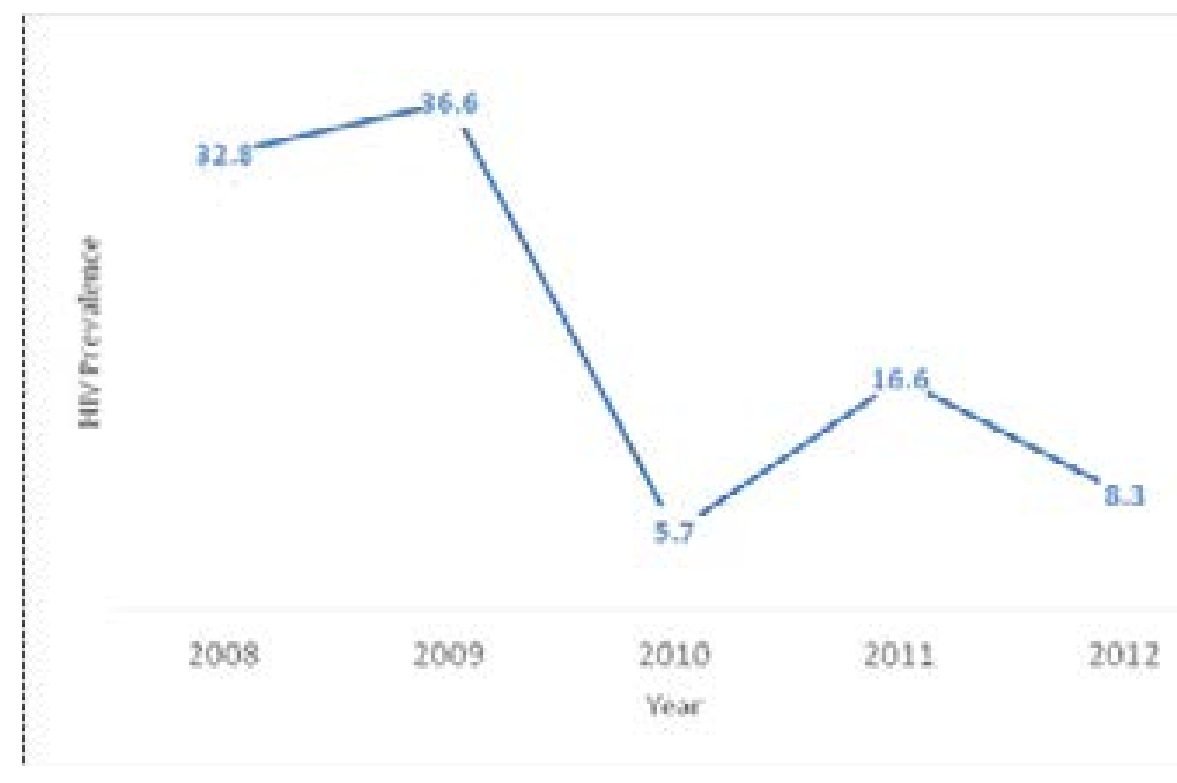

Trends in HIV prevalence among young adults in relation to age

Figure 4 shows the pattern of HIV occurrence among young adults in relation to age. The patterns in HIV occurrence in various age-groups were not well defined, which showed a peak in 26-30 years age-group (35.7\%), followed by 31-35 (27.4\%), 36-40 years (18.5\%), 21-25 years $(15.7 \%)$ and $16-20$ years age-group $(2.7 \%)$. The yearly HIV prevalence among age group 26-30 years showed the highest HIV prevalence in 2010 (38.1\%), 2008 (36.7\%), 2011 (35.9\%), 2009 (35.4\%) and 2012 $(31.3 \%)$ [Figure 4]. 


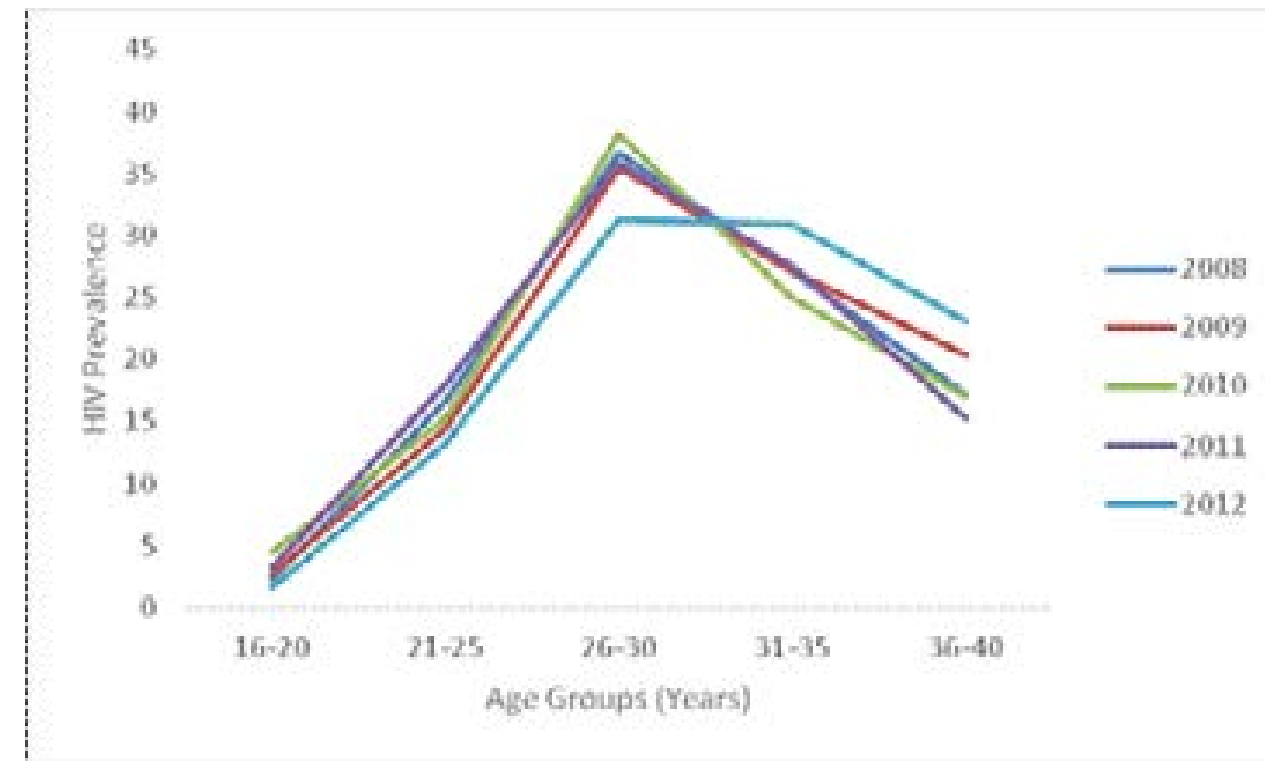

Trends in HIV prevalence among young adults in relation to sex

Figure 5 shows patterns in HIV occurrence in young adults in relation to sex. It indicated that 2,141 (69.5\%) HIV positive cases occurred in females and $940(30.5 \%)$ cases occurred in males. The study shows sex differences $(\mathrm{P}<0.05)$. The patterns of HIV prevalence among various sexes were not well defined, which showed a peak in 2008 (33.4\%) among males and in 2010 (73.3\%) among females [Figure 5].

Figure 5: Trends in HIV prevalence among young adults in relation to sex

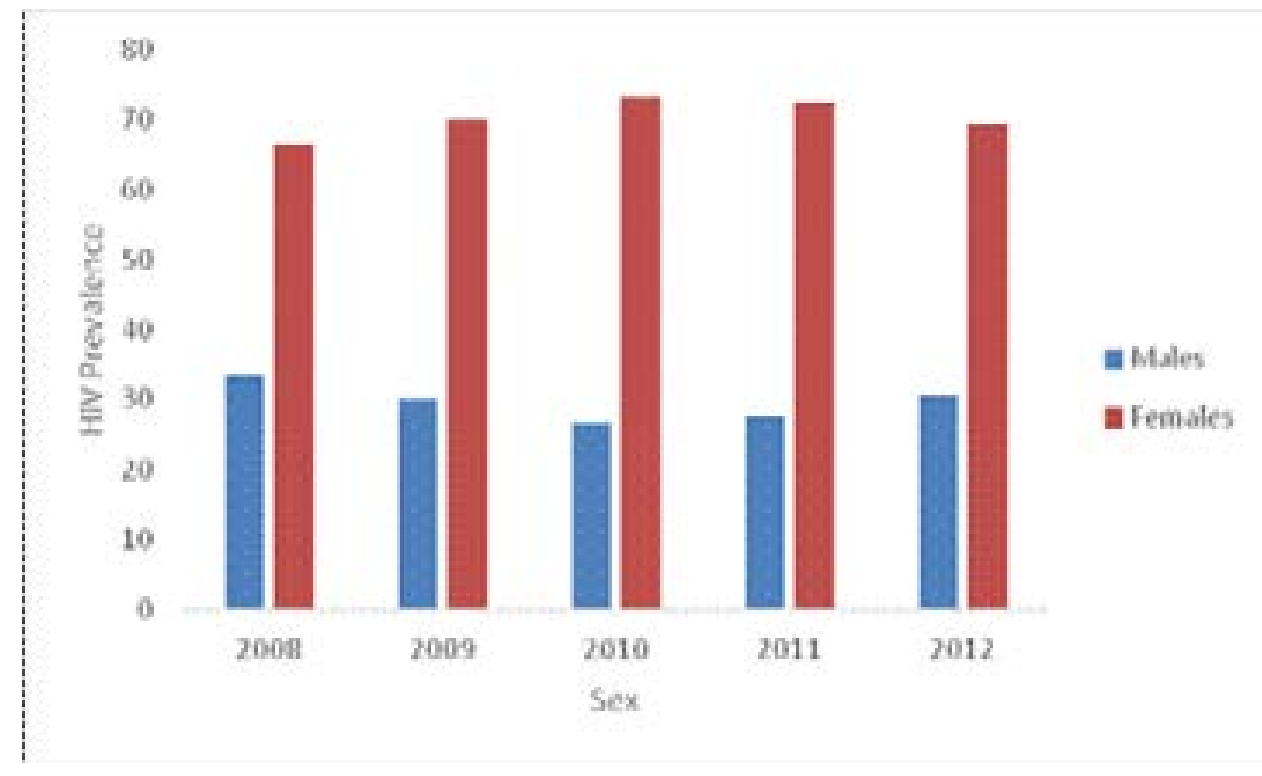

\section{Trends in HIV prevalence among males}

Figure 6 shows trends in HIV prevalence among males aged 16-40 years. The patterns of HIV prevalence among young adult males were not well defined, which showed a peak in 2008 (33.4\%), followed by 2012 (30.5\%), 2009 (29.9\%), 2011 (27.5\%) and 2010 (26.7\%).
More especially, among age groups 26-30 years which showed a uniform pattern of HIV prevalence with an increasing trend. While age groups $36-40$ years showed a decreasing trend except in 2009 with a higher prevalence $(34.1 \%)$. Other age groups shows inconsistent trend of HIV prevalence [Figure 6]. 


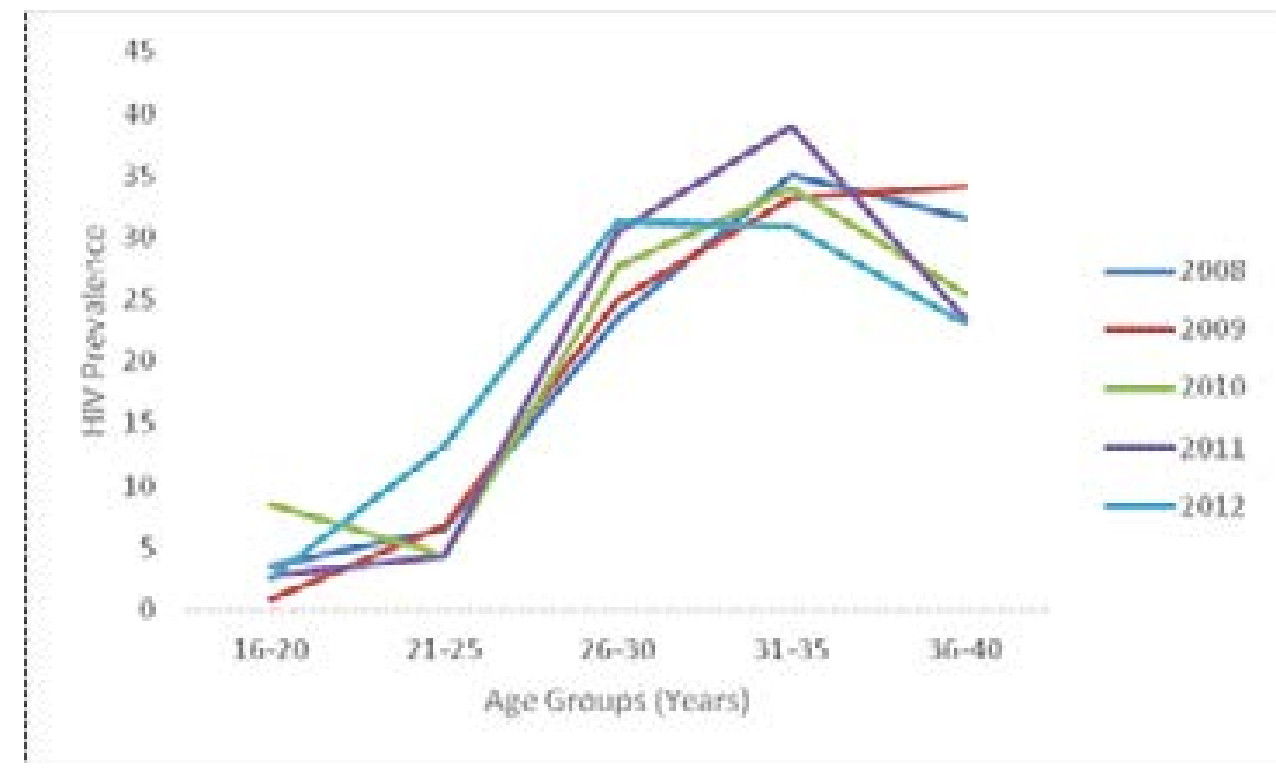

Trends in HIV prevalence among females

Figure 7 shows trends in HIV prevalence among females. The patterns of HIV prevalence among young adult females were not well defined, which showed a peak in $2010(73.3 \%)$, followed by 2011(72.5\%), $2009(70.1 \%), 2012(69.5 \%)$ and 2008(66.6\%). Similarly to their male counterparts, age groups $26-30$ years which showed a uniform pattern of HIV prevalence with an increasing trend from $21.7 \%$ in 2008 to $41.9 \%$ in 2010 and a decreasing trend from $41.9 \%$ in 2010 to $36.5 \%$ in 2012. Other age groups shows inconsistent trend in HIV prevalence [Figure 7].

Figure 7: Trends in HIV prevalence among females

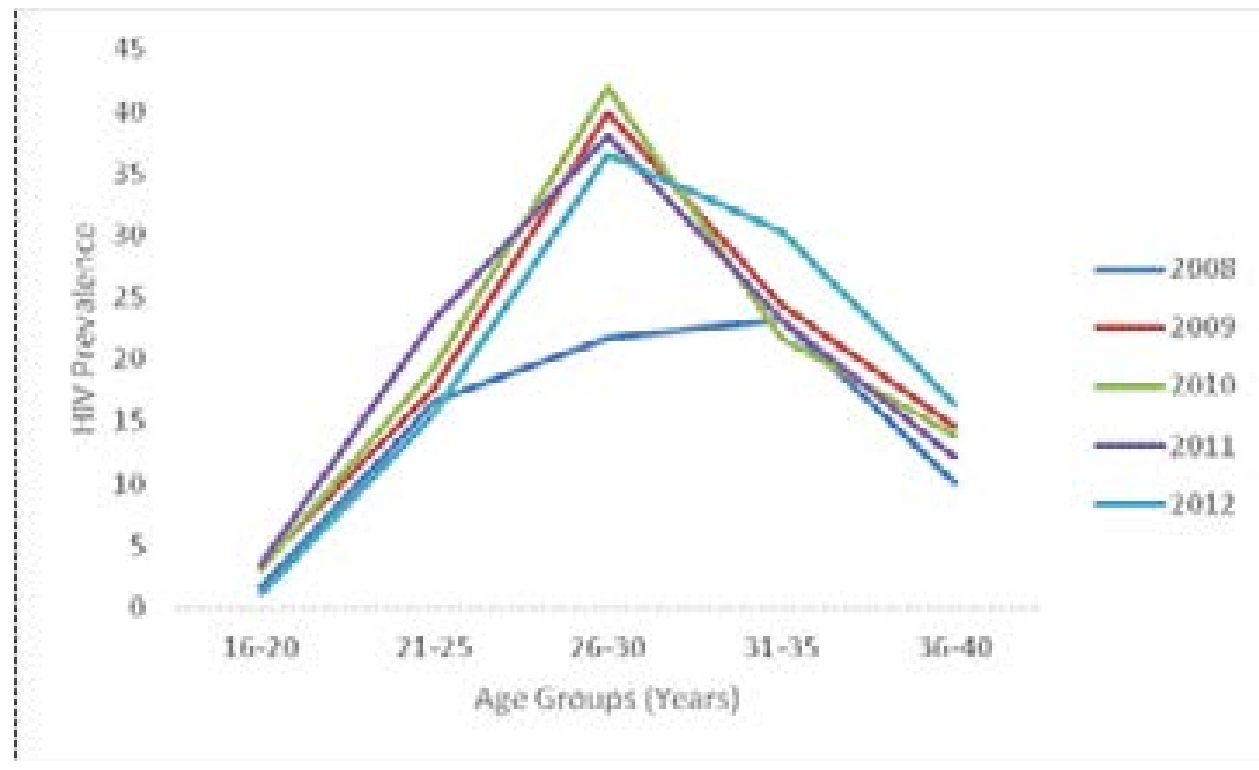


Trends in HIV prevalence among age groups 16-25 years

Figure 8 shows trends in HIV prevalence among younger adults (aged 16-25 years). The HIV occurrence dropped from $33.7 \%$ in 2008 to $6.2 \%$ in 2010 , increased to $19.3 \%$ in 2011 . However, HIV prevalence did not stabilized between 6.2\% (2010) and 6.7\% in 2012 [Figure 8].

\section{Figure 8: Trends in HIV prevalence among age groups $16-25$ years}

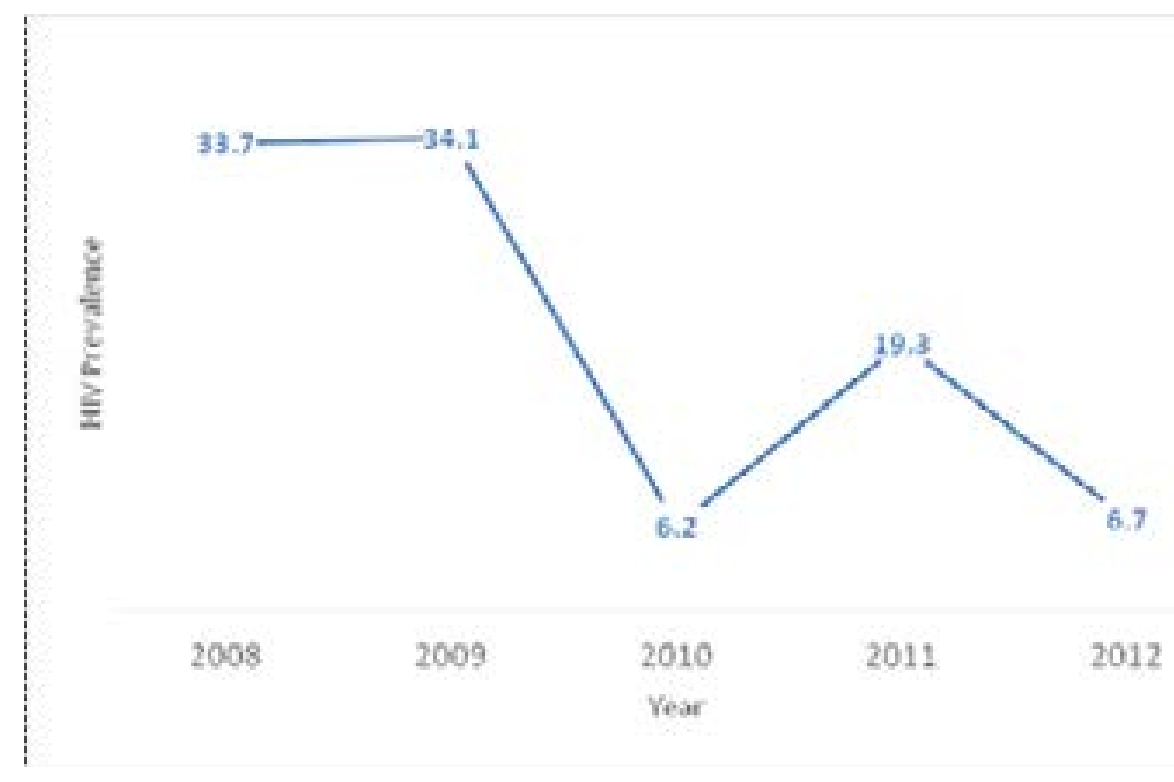

\section{Discussion}

Nigeria's HIV widespread is considered as one of the greatest fast cumulative rates of HIV and AIDS cases. Appraisal of the HIV sentinel study in Nigeria shows that HIV occurrence rate amplified progressively from $1.8 \%$ in 1991 to $3.8 \%$ in $1993,4.5 \%$ in $1996,5.4 \%$ in $1999,5.8 \%$ in 2001 , dropped insignificantly to $5.0 \%$ in 2003 and steadied between $4.4 \%(2005)$ and $4.1 \%$ in $2010^{17,33-38}$. Adeokun ${ }^{39}$ reported that geographic disparities in HIV occurrence might be due to earlier pivots of sexually transmitted infections (STIs) or urban expansion in Nigeria. Similarly, evaluation of the HIV national sentinel study revealed that HIV occurrence diverse meaningfully through geopolitical sites and amid dissimilar danger clusters in Nigeria ${ }^{40-42}$.

This is a retrospective study which aimed at assessing the trend of HIV prevalence among age groups 16-40 years in Port Harcourt, Rivers State, Nigeria. The trends in HIV prevalence were not well defined, which showed a peak in 2009 (36.6\%), followed by 2008(32.8\%), 2011(16.6\%), 2012(8.3\%) and 2010(5.7\%). There was a $3.8 \%$ increase in HIV prevalence from $32.8 \%$ in 2008 to $36.6 \%$ in 2009 . There was $30.9 \%$ decrease in HIV prevalence from $36.6 \%$ in 2009 to $5.7 \%$ in 2010 and this decrease could have been achieved due to proper awareness and implementation of policies (on patient management and disease control). Between 2010 and 2011 there was $10.9 \%$ increase in HIV prevalence and 8.3\% decrease in HIV prevalence between 2011 and 2012, these changes could also be traced to inconsistency in governance (corruption and frequent change or transfer of health officers). Conversely, the occurrence of HIV appeared to be steady between 2009 and 2012 as presented in previous studies- $36.6 \%$ (2009), 5.7\% (2010), 16.6\% (2011) and 8.3\% (2012). It is also striking that HIV occurrences in Rivers State have maintained high prevalence since 2009 compared to some other states in Nigeria ${ }^{17}$. A similar trend in HIV prevalences in Rivers State have maintained high prevalence since 2001 compared to some other states in Nigeria was previously observed ${ }^{17}$.

The trend of HIV prevalence among various agegroups were not well defined, which showed that HIV occurrences increased with growing age and highest at age groups $26-30$ years $(35.7 \%)$ after which it declined. This trend deviated from what was observed in the 
2010 national sentinel study ${ }^{17}$. In 2010, HIV occurrence was topmost among age-groups 30-34 years ${ }^{21}$. However in 2008, younger people age 20-29 years have the highest HIV prevalence of $4.9 \%{ }^{42}$ which is still within range in our present findings. The study shows sex differences $(\mathrm{P}<0.05)$ in the trend of HIV occurrence in young adults. It indicated that $69.5 \%$ cases of HIV occurred in females and $30.5 \%$ in males. Similar trend was also reported by United States Embassy in Nigeria ${ }^{13}$ with women above age 15 having the higher HIV prevalence $(52.0 \%)$ than men $(37.0 \%)$. A similar trend was also observed by $\mathrm{FMOH}^{17}$. The trend of HIV prevalence among various sexes were not well defined, which showed a peak in 2008 (33.4\%) among males and in $2010(73.3 \%)$ among females. Similar trend was reported by $\mathrm{FMOH}^{17}$. In 2007 national sentinel study, higher prevalence was reported among females $(4.0 \%)$ than males $(3.2 \%)^{26}$.

The trend analysis of HIV prevalence among male age-groups in this study were not well defined, which showed a peak in 2008 (33.4\%), followed by 2012 (30.5\%), 2009 (29.9\%), $2011(27.5 \%)$ and 2010 (26.7\%). More especially, among age groups 26-30 years which showed a uniform pattern of HIV prevalence with an increasing trend. While age groups 36-40 years showed a decreasing trend except in 2009 with a higher prevalence $(34.1 \%)$. Similar trend was observed by $\mathrm{FMOH}^{17}$. Also, the trend of HIV prevalence among female agegroups were not well defined, which showed a peak in 2010 (73.3\%), followed by 2011(72.5\%), 2009(70.1\%), $2012(69.5 \%)$ and $2008(66.6 \%)$. Similarly to their male counterparts, age groups 26-30 years which showed a uniform pattern of HIV prevalence with an increasing trend from $21.7 \%$ in 2008 to $41.9 \%$ in 2010 and a decreasing trend from $41.9 \%$ in 2010 to $36.5 \%$ in 2012 . Similar trend has also been previously reported ${ }^{17,43}$. The 2008 antenatal clinic (ANC) study presented uppermost HIV occurrence rate in females within 25-29 years $(5.6 \%)$ and $30-34$ years $(4.9 \%)$ age-groups ${ }^{43}$.

Trend analysis of HIV prevalence among age groups 16-25 years presented a steady drop from 2008-2010 (33.7\% (2008), 34.1\% (2009), and 6.2\% (2010). Then, a rise from $6.2 \%$ in 2010 to $19.3 \%$ in 2011 and decrease again to $6.7 \%$ (2012). The occurrence of HIV among various sexes within 16-25 years age-groups were not well defined, which showed a peak in 2012 (21.1\%) among males and 2011 (90.8\%) among females. Similar trend was reported by $\mathrm{FMOH}^{17}$. In the national trend analysis by $\mathrm{FMOH}^{17}$, the tendency among females within age groups 15-24 years (who were also seen as an guide to fresh cases of HIV) also progressively dropped from $6.0 \%$ in 2001 , through $5.3 \%$ in 2003 to $4.3 \%$ in 2005 , to $4.2 \%$ in 2008 , to $4.1 \%$ in $2010^{17}$. The HIV pattern in age-group 15-24years seemed to stable from 2005 to 2010 (amid $4.3 \%$ and $4.1 \%)^{17,21}$. This drifts might perhaps owing to the encouraging effects of the several precautionary interventions directed towards the youths and the cumulative access to ART across the nation, thus ensuing in enhanced survival rate amongst PLWHAs. Therefore, the necessity for population centered HIV investigation to advance HIV and AIDS diagnosis, research and scheduling in the country ${ }^{39,44}$.

Previously, an evaluation of the HIV sentinel studies in Nigeria indicates that HIV occurrence differed crossways geopolitical places in Nigeria ${ }^{1,40-42}$. Generally, HIV prevalence of $7.3 \%$ and $6.0 \%$ was reported for Rivers state during the 2008 and 2010 sentinel studies ${ }^{13,17}$. Restrictions have been recognised in the national HIV data for the reason that the proportions were built on HIV prevalence amongst pregnant women presenting at the government based health amenities, thus, slight information is known about HIV occurrences among broad-spectrum population or amongst males ${ }^{45}$. Likewise, information on incidence and prevalence rates among several vulnerable populations were unavailable from the study ${ }^{45}$. Similarly, a retrospective review by Sule et al. ${ }^{43}$ in Kogi State revealed increasing HIV seropositivity between 2002 and 2006 from 15.5 to $29.3 \%$.

However, the inconsistency in trend of HIV prevalence observed in this study is expected since Rivers State shared boundaries with state whose HIV prevalence has comparatively stayed higher between 2005 and 2010. There was a steady rising pattern of HIV frequency in states such as Abia, Akwa Ibom and Bayelsa States. Though, Akwa Ibom and Bayelsa States have upheld a piercing upsurge since 2005, Imo State had remained low $^{17}$. In the 2010 National HIV seroprevalence study, no constancy in the HIV trend in Rivers State, Nigeria 17. The HIV trend had varied between 1995 and 2010 in the Rivers State. According to $\mathrm{FMOH}^{17}$, there was a reliable rising trend in 3 years, namely 1995/1996 (1.0\%), 1999 (3.3\%) and 2001 (7.7\%). HIV prevalence in Rivers State has relatively dropped to $6.6 \%$ in 2003 and $5.4 \%$ in 2005. However, it rose to $7.3 \%$ in 2008 and dropped again to $6.0 \%$ in $2010^{13,17}$. 
In the same vein, Port Harcourt shared boundaries with area whose HIV prevalence has relatively remained higher with Bori as highest $(8.0 \%)$, followed by Bonny $(5.9 \%)$ then Port Harcourt $(5.5 \%)^{13,17}$. According to the 2010 National HIV seroprevalence study, Port Harcourt topmost initially $(7.0 \%)$, then fell to $3.7 \%$ in 2003 , rose to 5.1 in 2005 and upheld a rising trend getting to $7.0 \%$ in 2008 and dropped again to $5.5 \%$ in $2010^{17}$. Bori was initially high (7.9\%), then fell to $7.7 \%$ (2003), to 5.7 (2005) and upheld a rising trend getting to $8.3 \%$ (2008) and fell to $8.0 \%(2010)^{17}$. Bonny was initially high $(8.2 \%)$, then fell to $8.3 \%$ in $2003,6.0 \%$ in 2005 and kept a rising trend getting to $8.4 \%$ in 2008 and fell again to $5.9 \%$ in $2010^{17}$.

Also, according to the 2010 National HIV seroprevalence study, Uyo (Akwa-Ibom State) had taken related high occurrence of HIV 13.0\% in 2001, dropped to $5.7 \%$ in 2005 and progressively rose to $11.7 \%$ in $2010^{17}$. Sagbama (Bayelsa State) had taken the topmost urban occurrence of HIV $(12.7 \%)^{17}$. Iquita-Oron (Akwa-Ibom State) was topmost in the rural occurrence rate of HIV $(15.9 \%)^{17}$. Edeoha (Rivers State) had taken $3.8 \%$ prevalence of HIV and upheld the lowest rural prevalence of HIV while Eberi (Rivers State) had taken the topmost HIV prevalence $(5.8 \%)$ in the rural ${ }^{17}$. More detailed research is required to achieve a better understanding of the reasons for these varying patterns ${ }^{1,17,35}$.

All States in Nigeria have taken indiscriminate widespread of HIV since $2003^{17}$. The national pattern of HIV occurrence presented a stable rise from 1.8\% in 1991 to $4.5 \%$ in 1995 , to a top (5.8\%) in 2001 and dropped gradually to $4.4 \%$ in 2005 . It seemed to have stabilized from 2005-2010 (amid 4.4\% and 4.1\%) ${ }^{17}$. The low prevalence reported at the national level might be credited to the fact that the proportions of centers giving anti-retroviral therapy (ART) services rose from 24 in 2005 to about 400 in $2011^{14,46-48}$ in addition the United States President's Emergency Plan for AIDS Relief (PEPFAR) is presently assisting about 1,000 HIV counseling and testing centers in Nigeria ${ }^{14,46-48}$. Also in Nigeria, PEPFAR stated assisting over 441,000 persons on ART, 2.3 million on counseling and testing and 34,000 HIV-infected pregnant women on ART prophylaxis under prevention of mother-to-child-transmission programme $e^{14,46-48}$.

In 2006, the Rivers State Action Committee on AIDS (SACA) commenced the implementation of a Strate- gic Response Plan to prevent and mitigate the effect of HIV/AIDS by $2009^{4}$. The proportion of centers giving ART services in Rivers state rose from 2 (2005) to $8(2009)^{4}$ and has also increased recently. Health care facilities providing HIV/AIDS counselling and testing services also increased from $3.2 \%$ in 2005 to $20.5 \%$ in 2009, while SACA was changed to State Agency for the Control of AIDS (SACA) ${ }^{4}$.

Challenges facing responses to HIV infection in Nigeria has been insufficient quantity and geographical expansion of locations giving ART facilities; set-up, schemes, and staff prerequisite to appropriately monitor treatment maintenance and forfeiture are becoming progressively insufficient as programmes scale up; insufficient admittance to ART for both adults and children; and insufficient medical appointment system and connections between the diverse stages of health care and between facilities and community services ${ }^{21}$. Gaps included inadequate funding by the State government and development partners, poor linkages between SACA and other coordinating entities in the State and the skewed access to antiretroviral therapy services in favour of urban centres of the State 4 .

With concerted efforts are now in place to comprehensively tackle the epidemic of HIV; it still remains an issue that demands a systematic and highly tailored intervention. While the prevalence of HIV/AIDS appear stabilizing in Nigeria, to think that the trend cannot take an upward turn will be an understatement. Indeed, 'the prevalence of HIV will increase, while the future rate of new infections is uncertain ${ }^{39}$.

\section{Conclusion}

The HIV epidemic in Nigeria is concentrated mainly among heterosexuals, yet the trend is now shifting towards most-at-risk in the populations. The study on the trends in HIV prevalence among young adults in Rivers State, Nigeria showed that, there is unstable progress in the fight against HIV among young adults of age bracket (16-40 years). This trend analysis of HIV prevalence in this study showed that HIV infection has become endemic in Port Harcourt, Rivers State, Nigeria with a stabilizing seroprevelence of 5.7\% (2010), 16.6\% (2011) and 8.3\% (2012). From the results obtained, there was no well defined trend in prevalence of HIV among young adults in Rivers State, Nigeria. Although, there are rising and falling in the number of cases (frequencies), which could be attributed to inconsistency 
in policies or programmes concerning HIV victims in the state.

In view of this, it is essential that all the interested parties in Rivers State to uphold the current impetus of intermediations and swiftly increase these intermediations so as to keep the decreasing trend in HIV occurrences in Nigeria. The current struggles targeted at decreasing the prevalence of HIV and refining support services, management, treatment and care should be reinforced and extended. Enhanced and more strengthened surveillance system targeting the whole population and with special attention to the subgroup most-at-risk need to be implemented. Bearing in mind the study outcomes, we suggested that crucial preventive plans and strategies targeted at youth (among other groups) should be reinforced. More prevention campaigns should be planned and carried out while matters arising with increasing access to HIV testing, counselling, ART and care should be accessed. We also recommend that the current findings should be reflected alongside with other population-based study to account for the widespread of HIV in Port Harcourt, Rivers State, Nigeria.

\section{References}

1. Sule WF, Okonko IO, Yusuf OT, Donbraye E, Fadeyi A,Alli JA. 2010. HIV-1 and -2 Antibodies among Children in Anyigba, Kogi State, Nigeria. Asian Journal of Medical Sciences 2(4): 170-176

2. United Nation Programme on HIV/AIDS/World Health Organization (UNAIDS/WHO) Press Release (2005). HIV Infection Rates Decreasing in Several Countries but Globally Number of People Living with HIV Continue to Rise. Available at www.usaid.org/ epi/2005/doc/docs/PR_EPIUpdateNov05en.pdf:1-3 3. World Health Organization (WHO, 2005). Progress on global access to HIV antiretroviral therapy: An update on ' 3 by 5'. World Health Organization (June, 2005) ISBN 9241593393 http://www.who.int/3by5 p. 34.

4. Tobin-West CI and Okeh CM. 2012. HIV/AIDS response in Rivers State, Nigeria: an evaluation of accomplishments and gaps. Port Harcourt Medical Journal 2012, 6(3)

5. Erhabor O, Ejele OA, Nwauche CA, Akani C, Cosmos E, Allagoa D, Edward-Alikor A.D., Ojule AC, Opurum $\mathrm{H}$, Obunge $\mathrm{O}$, Babatunde S, Frank-Peterside N, Chinenye S, Anele IE, Adias TC, Uko E, Agbonlahor DE, Buseri FI, Jeremiah ZA, Wachuckwu C, Azuonwu O, Abbey SD, Onwuka F, Ebitimi EN, Seleye-Fubara D, Osadolor H (2011). Challenges Associated with the Ef- fective Managementof HIV Infection in a Low Income Setting in Sub-Saharan Africa: Case Study of Nigeria, HIV-infection - Impact, Awareness and Social Implications of living with HIV/AIDS, Dr. Eugenia Barros (Ed.), ISBN: 978-953-307-343-9, InTech,pp155-182. Available from: http://www.intechopen.com/books/ hiv-infection-impact-awareness-and-social-implications-of-living-with-hivaids/challenges-associatedwith-the-effective-management-of-hiv-infection-in-alow-income-setting-in-sub

6. Nsagha DS, Njunda AL, Kamga HLF, Assob JCN, Bongkem EA. 2012. HIV-1/HIV-2 co-infection among voluntary counselling and testing subjects at a regional hospital in Cameroon. African Health Sciences 2012; 12(3): $276-281$

7. Frank-Peterside N, Nneji LC, Okerentugba PO, Okonko IO. 2013. Prevalence of HIV-1 and HIV-2 antibodies in a cohort of street-involved youths in $\mathrm{Oy}$ igbo, Rivers State, Nigeria. World Rural Observations, 5(4): 33-36

8. Hall, H.I; Espinoza, L;Benbow, N; Hu Y.W. (2010). Urban Areas HIV Surveillance Workgroup.Epidemiology of HIV Infection in Large Urban Areas in the United States.PLoS One; 5(9).

9. Cheesbrough M. Human immunodeficiency virus (HIV). District Laboratory Practice in Tropical Countries. Part 2, Second Edition. Cambridge University Press. 2006; 253-265.

10. Sule WF, Adewumi MO, Samuel TC. (2009b). HIV specific antibodies among married pregnant women and female commercial sex workers attending voluntary counseling and HIV testing centre in Abuja, Nigeria. African Journal of Biotechnology 8 (6):941-948

11. Olaleye OD, Bernstein L, Kkueozor CC (1993). Prevalence of Human Immunodeficiency virus types 1 and 2 infection in Nigeria. Journal of Infectious Diseases, 16: $710-714$.

12. Abimiku AG, Zwanndo G, Kyari N, Opajobi S, Ibanga S, Guyit A (1994). HIV-1 not HIV-2 is present in Nigeria: Need for consideration in vaccines plans. Vaccine Res. 3(2): 101-103.

13. United States Embassy in Nigeria (2011). September 2011 Nigeria HIV Fact Sheet. Economic Section, Plot 1075, Diplomatic Drive Central Area Abuja, FCT, Nigeria. Website: http://nigeria.usembassy.gov

14. Burlew A, Puckett A, Bailey R, Caffrey M, Brantley $\mathrm{S}$. Assessing the relevance, efficiency, and sustainability of HIV/AIDS in-service training in Nigeria. Human Resources for Health 2014, 12:20

15. Frymus D, Schaefer L, Wuliji T: Improving the efficiency, effectiveness and sustainability of health worker 
in-service training: closing the gaps between evidence, practice and outcomes. Human Resource Health 2013, 11. http://www.human-resources-health.com/series/ IST.

16. World Bank: Nigeria Data. 2012. http://data.worldbank.org/country/Nigeria.

17. Federal Ministry of Health (FMOH, 2010). A TECHNICAL REPORT on 2010 National HIV Sero-prevalence Sentinel Survey. Department of Public Health, National AIDS/STI Control Programme, Federal Ministry of Health, Abuja, Nigeria. Pp97

18. World Health Organization/African Regional Office (WHO/AFRO, 2001). HIV surveillance report for Africa 2000. Harare, Zimbabwe; 2001 November.

19. World Bank (2008). Nigeria report final CHA World Bank 14 July08.doc. pp1-31

20. UNAIDS (2010). UNAIDS Report on the global HIV/AIDS epidemic update, 2010. Geneva: Switzerland. Retrieved from http://www.unaids.org/en/regionscountries/countries.

21. National Agency For The Control Of AIDS (NACA, 2011).Update on the HIV/AIDS Epidemic and Response In Nigeria. Fact Sheet 2011 - NACA Status Report.

22. Nigeria National Agency for the Control of AIDS (2012). Global AIDS Response: Country Progress Report. Abuja, Nigeria : GARPR. Available:

http://www.unaids.org/en/dataanalysis/knowyourresponse/countryprogressreports/2012countries/Nigeria $\% 202012 \% 20$ GARPR $\% 20$ Report $\% 20$ Revised.pdf. Accessed 7 February 2013.

23. Nigeria National Agency for the Control of AIDS (2010). National HIV/AIDS Strategic Plan 2010-2015. Abuja, Nigeria: Nigeria National Agency for the Control of AIDS. Available: http://nigeria.unfpa.org/pdf/ nsp.pdf. Accessed 9 February 2013.

24. Eze, J.I. (2009) Modeling HIV/AIDS Epidemic in Nigeria. PhD Thesis, University of Glasgow.

Available: http://theses.gla.ac.uk/642/1/2009EzePhD. pdf. Accessed 6 February 2013.

25. Joint United Nations Programme on HIV and AIDS (2012). Global report: UNAID report on global AIDS epidemic, 2012 Available: http://www.unaids.org/en/ media/unaids/contentassets/documents/epidemiology/2012/gr2012/20121120_UNAIDS_Global_Report_2012_with_annexes_en.pdf.Accessed 5 February 2013.

26. National HIV/AIDS and reproductive health survey (NARHS, 2007). Federal Ministry of Health, Federal Republic of Nigeria, Abuja, Nigeria.
27. Njoku, O.N.(2008). "Eastern Nigeria Under British Rule" (PDF). Department of History, University of Nigeria (University of Nigeria, Nsukka): p23.

28. Mbakwem-Aniebo, C; Ezekoye,C.C. and Okonko, I.O. (2012a). Detection of HIV-1 and -2 Antibodies among freshmen of the University of Port Harcourt, Port Harcourt, Southern Nigeria. World Applied Sciences Journal 16 (8): 1087-1092.

29. Mbakwem-Aniebo C, Ezekoye CC, Okonko IO. 2012b. Knowledge About HIV/AIDS, and Reported Risk Behaviours Among Freshmen of The University of Port Harcourt, Port Harcourt, Southern Nigeria. World Applied Sciences Journal 16 (8): 1093-1103

30. National Population Commission (NPC, 2006). Census of the Federal Republic of Republic of Nigeria. 31. Ogbonna, D.N., G.T. Amangabara, and T.O. Ekere. (2007). "Urban solid waste generation in Port Harcourt metropolis and its implications for waste management", Management of Environmental Quality: An International Journal, Volume: 18 Issue: 1.

32. Oje OJ, Sule WF and Famurewa D. Dual Positivity of Hepatitis B Surface Antigen and Anti-Hepatitis C Virus Antibody and Associated Factors Among Apparently Healthy Patients of Ekiti State, Nigeria. Viral Immunology, 2012; 25(6): 448-455

33. Sofo, C.A. Ali-Akpajiak and Toni Pyke (2003) 'Social development and poverty in Nigeria', Chapter 3 in 'Measuring poverty in Nigeria', Oxfam Working Paper. 34. Federal Ministry of Health (FMOH, 2004). Summary Findings from the 2003 National HIV Seroprevalence Sentinel Survey inNigeria. Information for Policy Makers. Pp12-38

35. Federal Ministry of Health (FMOH, 2006). Epidemiology of HIV/AIDS: The 2005 National HIV/ Syphilis Sentinel Survey among pregnant women in Antenatal Clinic in Nigeria in Collaboration with CDC, WHO, NACA, DFID, APIN, USAIDS, EHHANSE. Technical Report 4: 30-39

36. Alikor DE, Erhabor NO (2005). Trends of HIV-Seropositivity among Children in a Tertiary Health Institution in the Niger Delta Region of Nigeria. African Journal of Health Sciences, 12: 108-113

37. United Nation Programme on HIV/AIDS (UNAIDS, 2008). Report on the Global AIDS Epidemic.http://www.unaids.org/epi/2008/doc/EPIupdate2008_pdf_en/epi-update2008_en.pdf;http:// www.slideshare.net/UNAIDS/global-summary-of-the-aids-epidemic-2008-2572046. Accessed February 24, 2010 
38. Avert Organization (2010). HIV and AIDS in Africa. http://www.avert.org/hiv-aids-africa.htm, Accessed February 24, 2010.

39. Adeokun L (2006). Social and Cultural Factors Affecting the HIV Epidemic. In AIDS in Nigeria: A Nation on the Threshold. Edited by Olusoji Adeyi, Phyllis J. Kanki, Oluwole Odutolu, John A. Idoko. Havard Center for Population and Development Studies, 9 Bow Street, Cambridge, MA 02138 USA. pp.151-173.

40. Federal Ministry of Health (FMOH, 2003) Technical Report 2003 National HIV Sero-prevalence Sentinel Survey. Federal Ministry of Health.

41. Olaleye DO, Tekena OH, Odaibo GN (2006). The Virology and Dynamics of the Epidemic: In- AIDS in Nigeria: A Nation on the Threshold. Edited by: Olusoji Adeyi, Phyllis J. Kanki, Oluwole Odutolu, John A. Idoko. Havard Center for Population and Development Studies, 9 Bow Street, Cambridge, MA 02138 USA. pp. 37-66.

42. Utulu SN, Lawoyin TO (2007). Epidemiological features of HIV infection among pregnant women in Makurdi, Benue State, Nigeria. Journal of Biosocial Science, 39: 397-408.

43. Federal Ministry of Health, Nigeria (2008). Technical report on the national HIV sero-prevalence sentinels survey. Federal Ministry of Health, Abuja, Nigeria
44. Sule WF, Enemuor SC, Adewumi MO, Attah OC. (2009a). Traditional crop farmers in Kogi East, Nigeria elucidate elevated HIV and AIDS prevalence level during a five -year study period. African Journal of Microbiology Research 3(4): 128-132

45. Federal Ministry of Health (FMOH, 2001). Technical Report 2001 National HIV/Syphilis Sentinel Survey among Pregnant Women Attending Antenatal Clinics in Nigeria. Abuja: Federal Ministry of Health.

46. United States Government Interagency Team (USG Team): Nigeria Global Health Initiative Strategy 2010 to 2015. Abuja, Nigeria: USG Team; 2011. http:/ /www. ghi.gov/whereWeWork/docs/NigeriaStrategy.pdf.

47. United States Embassy in Nigeria: Nigeria HIV Fact Sheet. Abuja, Nigeria: United States Embassy in Nigeria; 2011. http://photos.state.gov/libraries/nigeria/487468/pdfs/December $\% 20$ HIV\%20Fact $\% 20$ Sheet.pdf.

48. United States President's Emergency Plan for AIDS Relief (PEPFAR): Partnership to Fight HIV/AIDS in Nigeria. 2012. http://www.pepfar.gov/documents/organization/199599.pdf.

49. Nikolopoulos, G., Paraskevis, D.,\&Hatzakis, A. (2008). HIV epidemiology in Greece. FutureMicrobiology 3 (5), 507-516. Available: http://www.futuremedicine.com/doi/abs/10.2217/17460913.3.5.507. 